\title{
Evaluation on the Intrinsic Physicoelectrochemical Attributes and Engineering of Micro-, Nano-, and 2D-Structured Allotropic Carbon- Based Papers for Flexible Electronics
}

\author{
Supatinee Kongkaew, Lingyin Meng, Warakorn Limbut, Proespichaya Kanatharana, \\ Panote Thavarungkul, and Wing Cheung Mak*
}

Cite This: Langmuir 2021, 37, 14302-14313

Read Online

ACCESS | Lلll Metrics \& More | 回 Article Recommendations ｜ sl Supporting Information

ABSTRACT: Flexible electronics have gained more attention for emerging electronic devices such as sensors, biosensors, and batteries with advantageous properties including being thin, lightweight, flexible, and low-cost. The development of various forms of allotropic carbon papers provided a new dry-manufacturing route for the fabrication of flexible and wearable electronics, while the electrochemical performance and the bending stability are largely influenced by the bulk morphology and the micro-/ nanostructured domains of the carbon papers. Here, we evaluate systematically the intrinsic physicoelectrochemical properties of allotropic carbon-based conducting

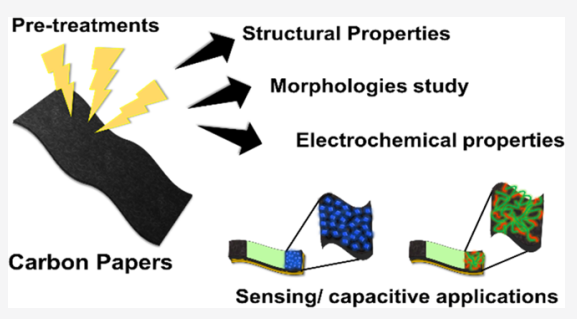
papers as flexible electrodes including carbon-nanotubes-paper (CNTs-paper), graphene-paper (GR-paper), and carbon-fiber-paper (CF-paper), followed by functionalization of the allotropic carbon papers for the fabrication of flexible electrodes. The morphology, chemical structure, and defects originating from the allotropic nanostructured carbon materials were characterized by scanning electron microscopy (SEM) and Raman spectroscopy, followed by evaluating the electrochemical performance of the corresponding flexible electrodes by cyclic voltammetry and electrochemical impedance spectroscopy. The electron-transfer rate constants of the CNTs-paper and GR-paper electrodes were $\sim 14$ times higher compared with the CF-paper electrode. The CNTs-paper and GR-paper electrodes composed of nanostructured carbon showed significantly higher bending stabilities of 5.61 and 4.96 times compared with the CF-paper. The carbon-paper flexible electrodes were further functionalized with an inorganic catalyst, Prussian blue (PB), forming the PB-carbon-paper catalytic electrode and an organic conducting polymer, poly(3,4-ethylenedioxythiophene) (PEDOT), forming the PEDOT-carbon-paper capacitive electrode. The intrinsic attribute of different allotropic carbon electrodes affects the deposition of PB and PEDOT, leading to different electrocatalytic and capacitive performances. These findings are insightful for the future development and fabrication of advanced flexible electronics with allotropic carbon papers.

\section{INTRODUCTION}

Flexible electronics have gained considerable attention for the development of newly emerging flexible and wearable electronic devices, including sensors and biosensors, batteries and capacitors, E-electronics and displays, etc., owing to their advantageous physicoelectrochemical properties including being lightweight, flexible, thin, and low-cost. ${ }^{1}$ Among all of the components in flexible electronics, the fabrication of flexible electrodes is crucially important. Current methods for fabrication of flexible electrodes can mainly be classified into the "bottom-up approach" such as wet chemistry based on the printing of conducting precursor inks or deposition of a conducting layer onto a flexible substrate ${ }^{2,3}$ and the "top-down approach" via shaping of a bulk prefabricated conducting flexible substrate into electrodes (e.g., carbon or metal sheet). For the wet-chemistry approach, various mask-based and maskfree printing techniques such as gravure printing, screenprinting, stencil printing, and inkjet printing were developed for the deposition of different conducting inks onto a substrate to create patterned electrodes. ${ }^{4}$ However, the wet-chemistry approach based on the printing of conducting inks has several limitations such as the extensive use of solvents for ink formulation, the requirement of an additional screen, stencil, or mask to pattern the conducting inks (except for inkjet printing), and a high-temperature ink curing process, ${ }^{5}$ while the vapor evaporation methods require expensive instruments for flexible electrode fabrication. Alternatively, other additive manufacturing approaches, including 3D printing, ${ }^{6}$ pencil drawing, ${ }^{7}$ and laser-direct writing, ${ }^{8,9}$ has been introduced for electrode fabrication. In contrast, the top-down approach using a prefabricated conducting flexible substrate that was produced in large scale by casting/assembling of nano-/microscopic

Received: August 9, 2021

Revised: November 18, 2021

Published: December 3, 2021 
conducting materials into macroscopic paperlike substrate offers a new route for the facile fabrication of advanced flexible electronic devices. ${ }^{10,11}$

Impacted by nanotechnology, the electrochemical properties of electronic or bioelectronic devices were largely improved by utilizing advanced allotropic materials such as various forms of metal nanoparticles (NPs) and nanorods; ${ }^{12-15}$ nanostructured and two-dimensional (2D)-structured carbon-based materials; $^{16-19}$ and nanostructured conducting polymers. ${ }^{20-23}$ Among all, carbon-based materials (e.g., graphite, glassy carbon, carbon fiber) are the most commonly used electrode materials. Conventional carbon has many advantageous properties such as good electrical and thermal conductivities, good chemical stability, biocompatibility, wide operational window potential, and low background current. ${ }^{24-26}$ Beyond that, advanced nanostructured allotropic carbon such as carbon nanotubes and graphene with enhanced conductivity, faster electron-transfer rate, and higher surface area with improved electrode kinetics are promising materials for emerging electronic device applications. ${ }^{27,28}$ Furthermore, advanced organic and inorganic materials, such as $\mathrm{ZnP}$ nanosheets, ${ }^{9}$ metal nanoparticles, ${ }^{29,30}$ nickel sulfide nanocomposites, ${ }^{31}$ and poly(3,4-ethylenedioxythiophene) (PEDOT), ${ }^{32}$ were incorporated with allotropic carbon electrodes with improved conductivity and capacitive and electrochemical sensing performance.

Driven by the emerging conducting paper industry, great efforts have been devoted to the development of allotropic carbon papers with light weight and flexibility, such as carbonfiber paper (CF-paper), carbon nanotubes paper (CNTs-paper, also known as bucky paper), and graphene-paper (GR-paper), as electrodes for various application fields including supercapacitors, $^{33}$ lithium-ion batteries, ${ }^{34}$ electrocatalysis, ${ }^{35}$ and sensors and biosensors. ${ }^{11}$ The use of these prefabricated conducting papers does not require wet chemistry or an additional mask for printing and high-temperature curing processes, while the fabrication of the flexible electrode can be achieved by simple cutting/xurography and paper assembling. For the development of high-performance carbon-paper-based flexible electrodes, it is important to understand the intrinsic nano-/microscale characteristics of carbon nanotubes, graphene, and carbon fiber within the assembled bulk conducting papers such as morphology, chemical characteristic, and defects originating from allotropic nano-/microstructured carbon materials, as well as the mechanical bending stability, electrochemical properties, and their price-to-performance aspect so as to provide a comprehensive study on the utilization of conducting papers for the development of various flexible electronics.

Here, we aim to perform a comprehensive evaluation of the intrinsic physicoelectrochemical properties of allotropic carbon-based conducting papers as flexible electrode platforms. We further demonstrate the engineering and assembling of nano-/microstructured carbon papers for the development of flexible electrodes for sensing and energy applications. The morphology and the chemical structure of different allotropic carbon papers including CNTs-paper, GR-paper, and CF-paper were characterized, followed by systematic evaluation and mapping of their morphology and structural properties with the electrochemical performance characterized by cyclic voltammetry $(\mathrm{CV})$ and electrochemical impedance spectroscopy (EIS). We also studied the mechanical bending stability of allotropic carbon papers as flexible electrodes. We demonstrated the postmodification performance of allotropic carbon papers with an inorganic catalyst, Prussian blue (PB), forming the PB-carbon-paper electrode for electrochemical sensing applications and an organic conducting polymer, poly(3,4-ethylenedioxythiophene) (PEDOT), forming the PEDOT-carbon-paper electrode for energy applications.

\section{EXPERIMENTAL SECTION}

Materials. Disodium hydrogen phosphate monohydrate $\left(\mathrm{Na}_{2} \mathrm{HPO}_{4} \cdot \mathrm{H}_{2} \mathrm{O}\right)$ and potassium dihydrogen phosphate $\left(\mathrm{KH}_{2} \mathrm{PO}_{4}\right)$ were obtained from Merck (Darmstadt, Germany). Hydrogen peroxide $\left(\mathrm{H}_{2} \mathrm{O}_{2}\right)$, potassium ferrocyanide $\left(\mathrm{K}_{4}\left[\mathrm{Fe}(\mathrm{CN})_{6}\right]\right)$, hydrochloric acid $(\mathrm{HCl})$, isopropanol $\left(\left(\mathrm{CH}_{3}\right)_{2} \mathrm{CHOH}\right)$, potassium ferricyanide $\left(\mathrm{K}_{3}\left[\mathrm{Fe}(\mathrm{CN})_{6}\right]\right)$, potassium chloride $(\mathrm{KCl})$, iron(III) chloride $\left(\mathrm{FeCl}_{3}\right)$, 3,4-ethylenedioxythiophene (EDOT), and poly(styrene sulfonate) (PSS) were purchased from Sigma-Aldrich (Louis). All chemicals were of analytical reagent grade. The phosphate buffer solution (PBS, $0.1 \mathrm{M}, \mathrm{pH}$ 7.4) was prepared by mixing a stock solution of $\mathrm{KH}_{2} \mathrm{PO}_{4}$ and $\mathrm{Na}_{2} \mathrm{HPO}_{4}$. All solutions were prepared using deionized water (Milli-Q purification system, MerckMillpore, MA). CNTs-paper (Bucky paper, 60 GSM, measured thickness $356 \pm 6 \mu \mathrm{m}$, weight per area $\left.5.904 \pm 0.005 \mathrm{mg} \mathrm{cm}^{-2}\right)$ was purchased from Nanotech Lab (NC). GR-paper (measured thickness $195 \pm 9 \mu \mathrm{m}$, weight per area $\left.21.70 \pm 0.01 \mathrm{mg} \mathrm{cm}^{-2}\right)$ was purchased from Sigma-Aldrich (Louis). CF-paper (measured thickness $188 \pm 2$ $\mu \mathrm{m}$, weight per area $8.56 \pm 0.00 \mathrm{mg} \mathrm{cm}^{-2}$ ) was purchased from FullCellStore (TX). Plastic sheet and double-sided adhesive tape were purchased from Biltema (Linköping, Sweden).

Activation of Allotropic Conducting Carbon Papers. Two different techniques were employed for the activation of allotropic conducting carbon papers including chemical treatment with isopropanol and physical treatment with oxygen plasma. In brief, for chemical pretreatment, carbon papers were immersed in isopropanol for $10 \mathrm{~min}$, followed by drying inside an incubator at $100{ }^{\circ} \mathrm{C}$ for $1 \mathrm{~h}$. In this process, the excessive surfactant or impurity contamination that comes from the manufacturing can be eliminated, exposing the original carbon-based material properties. ${ }^{36}$ For physical pretreatment, carbon papers were activated with oxygen plasma for 1 min (Diener electronic, Plasma Surface Technology, Pico, Germany). In this process, the free radicals, ions, and UV radicals are bombarded on the carbon surface, causing the phenomenon of decomposition and oxidation on the materials. Consequently, functional groups of oxygen are created on the carbon surface, inducing physical/chemical change on the surface of carbon-based papers. ${ }^{37,3}$

Assembling of Flexible Allotropic Carbon-Paper Electrodes. Allotropic carbon-paper electrodes were prepared by aligning and assembling the different carbon papers over a supporting plastic sheet with a double-sided adhesive tape. The assembled carbon-paper/ plastic sheet was then cut into electrode strips with a dimension of 30 $\mathrm{mm}$ length $\times 5 \mathrm{~mm}$ width using an electronic cutting machine (ScanNcut CM900, Brother Industries, Japan), followed by the encapsulation of electrode strips with an insulating adhesive tape ( $\sim 20 \mathrm{~mm}$ length). An active carbon working electrode was exposed with a surface area of $5 \times 5 \mathrm{~mm}^{2}$, as shown in Figure $2 \mathrm{a}$.

Preparation of Prussian Blue-Functionalized Allotropic Carbon-Paper Electrodes. Prussian blue (PB) was deposited onto the allotropic carbon-paper electrodes by applying a constant potential at $0.4 \mathrm{~V}$ for $300 \mathrm{~s}$ in $1 \mathrm{M} \mathrm{KCl}$ and $3 \mathrm{mM} \mathrm{HCl}$ containing 1 $\mathrm{mM} \mathrm{K}_{3}\left(\mathrm{Fe}(\mathrm{CN})_{6}\right)$ and $1 \mathrm{mM} \mathrm{FeCl}_{3}$. Then, the PB-modified carbonbased electrodes were activated in a $0.1 \mathrm{M} \mathrm{KCl}$ and $0.01 \mathrm{M} \mathrm{HCl}$ solution by cycling at the potential range between -0.2 and $0.6 \mathrm{~V}$ with a scan rate of $0.05 \mathrm{~V} \mathrm{~s}^{-1}$ for 10 cycles. The PB-modified carbonbased electrodes were kept in a dark location at room temperature before being used.

Preparation of PEDOT-Functionalized Allotropic CarbonPaper Electrodes. PEDOT was deposited onto the allotropic carbon-paper electrodes by dynamic potential cycling between 0 and $1.2 \mathrm{~V}$ with a scan rate of $0.1 \mathrm{~V} \mathrm{~s}^{-1}$ in a solution containing $10 \mathrm{mM}$ PEDOT and $2 \mathrm{mg} \mathrm{mL}^{-1}$ PSS for 20 cycles. Then, the PEDOT- 


\section{CNTs-paper}

(a)

(b)

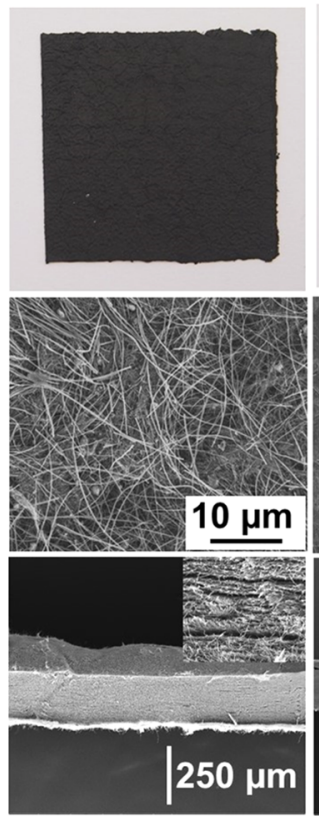

(d)

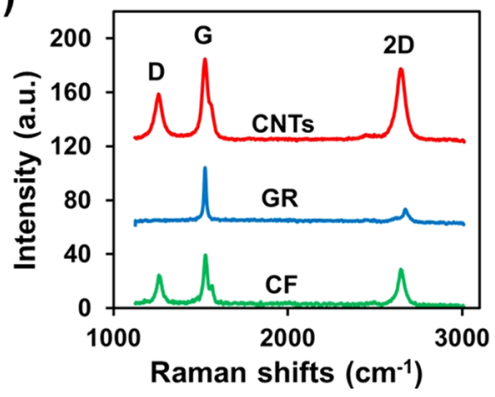

GR-paper

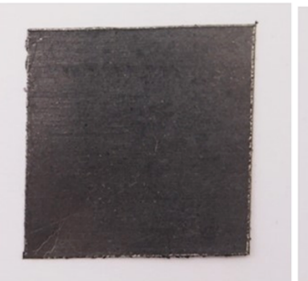

CF-paper

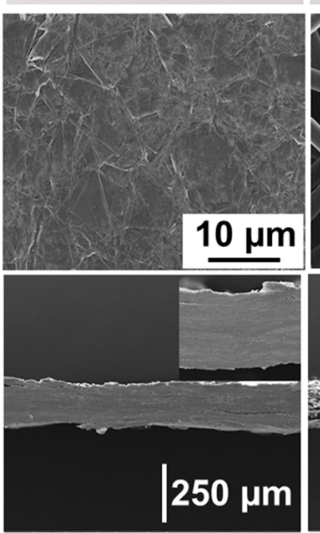

(e)

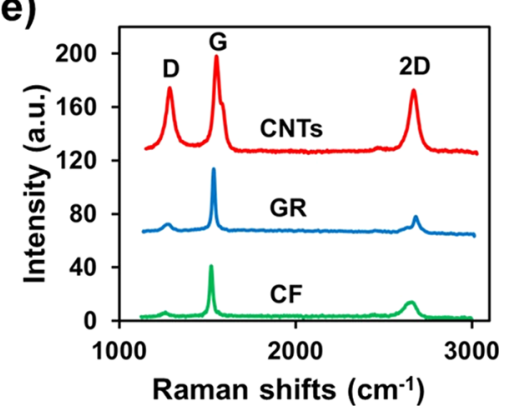

Figure 1. (a) Photographs of CNTs-paper, GR-paper, and CF-paper. (b) Top view and (c) cross-sectional view of SEM images for CNTs-paper, GR-paper, and CF-papers. (c) Inset shows high magnification. (d) Raman spectra of original allotropic carbon papers CNTs-paper (red line), GRpaper (blue line), and CF-paper (green line). (e) Raman spectra of allotropic carbon papers CNTs-paper (red line), GR-paper (blue line), and CFpaper (green line) after pretreatment with isopropanol, plasma, and isopropanol, respectively.

modified carbon-based electrodes were activated in a $0.1 \mathrm{M} \mathrm{KCl}$ solution by dynamic potential cycling between 0 and $0.5 \mathrm{~V}$ with a scan rate of $0.1 \mathrm{~V} \mathrm{~s}^{-1}$ for 10 cycles.

Characterizations and Electrochemical Measurements. The electrode morphology was characterized by a scanning electron microscope (SEM, LEO 155 Gemini, Zeiss, Germany). The element composition and mapping were determined by energy-dispersive $\mathrm{X}$ ray spectroscopy (EDS, Oxford Instruments). Raman spectra were acquired with a LabRAM HR 800 Raman spectrometer (Horiba Jobin Yvon, France) using a $660 \mathrm{~nm}$ laser with a power of $5 \mathrm{~mW}$.

All of the electrochemical measurements were performed by a BiPotentiostat/galvanostat $\mu$ Stat400 (Metrohm DropSens, S.L., Spain) at room temperature in an electrochemical cell consisting of a platinum wire, a silver/silver chloride $(\mathrm{Ag} / \mathrm{AgCl})$ electrode, and carbon paper as an auxiliary electrode, a reference electrode, and a working electrode, respectively. Electrochemical impedance spectroscopy was performed in $0.1 \mathrm{M} \mathrm{KCl}$ solution containing $5 \mathrm{mM}$ $\left[\mathrm{FeCN}_{6}\right]^{3-/ 4-}$ over the frequency range of $100 \mathrm{kHz}-0.01 \mathrm{~Hz}$ with a voltage amplitude of $5 \mathrm{mV}$. The impedance spectra were then analyzed with ZSimpWin Software (AMETEK Scientific instruments).

\section{RESULTS AND DISCUSSION}

Characterizations of the Bare 2D-, Nano-, and Microstructured Allotropic Carbon-Based Conducting
Paper Substrates. The physical appearance of different allotropic carbon papers is shown in Figure 1a. All of the carbon papers appear as thin paperlike sheets with a fairly homogeneous flat surface. Figure $1 b, c$ shows the top view and cross-sectional view of scanning electron microscopy (SEM) images for different bare allotropic carbon papers including CNTs-paper, GR-paper, and CF-paper. It shows that the micro-/nanofeatures of the CNTs, GR, and CF are retained after the allotropic carbon is compressed into paper sheets. For CNTs-paper, the surface morphology appears as an interconnected CNT network forming a porous film structure and the cross-section image shows a multilayer structure of assembled CNTs. For GR-paper, the surface morphology is smooth and compact, which is composed of multilayer stacking of GR nanosheets, while the cross-sectional image shows some pieces of delaminated GR nanosheets. For CF-paper, it is composed of horizontally arranged microscale CF with large gaps between individual fibers forming a relatively loose film structure, and the cross-sectional image showed a multilayer structure of CF. In addition, the thickness of allotropic carbonpapers was measured by cross-section SEM image (Figure 1c). The thicknesses of CNTs-paper, GR-paper, and CF-papers were $356 \pm 6,195 \pm 9$, and $188 \pm 2 \mu \mathrm{m}$, respectively. The 
Table 1. Raman Spectroscopy Parameters of Allotropic Carbon-Based Conducting Papers before and after Pretreatment

\begin{tabular}{|c|c|c|c|c|c|c|}
\hline \multirow[b]{2}{*}{ electrode materials } & \multirow[b]{2}{*}{ treatment } & \multicolumn{3}{|c|}{ Raman shift $/ \mathrm{cm}^{-1}$} & \multirow[b]{2}{*}{ ratio of $I_{\mathrm{D}} / I_{\mathrm{G}}$} & \multirow[b]{2}{*}{ FWHM of $\mathrm{G}$ band $/ \mathrm{cm}^{-1}$} \\
\hline & & $\mathrm{D}$ band & G band & $2 \mathrm{D}$ band & & \\
\hline CNTs-paper & before treatment & 1330 & 1584 & 2654 & 0.54 & 37.4 \\
\hline GR-paper & & & 1582 & 2681 & & 13.8 \\
\hline CF-paper & & 1330 & 1585 & 2655 & 0.56 & 24.2 \\
\hline CNTs-paper & after treatment & 1330 & 1584 & 2656 & 0.64 & 40.4 \\
\hline GR-paper & & 1341 & 1583 & 2681 & 0.10 & 14.0 \\
\hline CF-paper & & 1332 & 1581 & 2676 & 0.09 & 18.2 \\
\hline
\end{tabular}
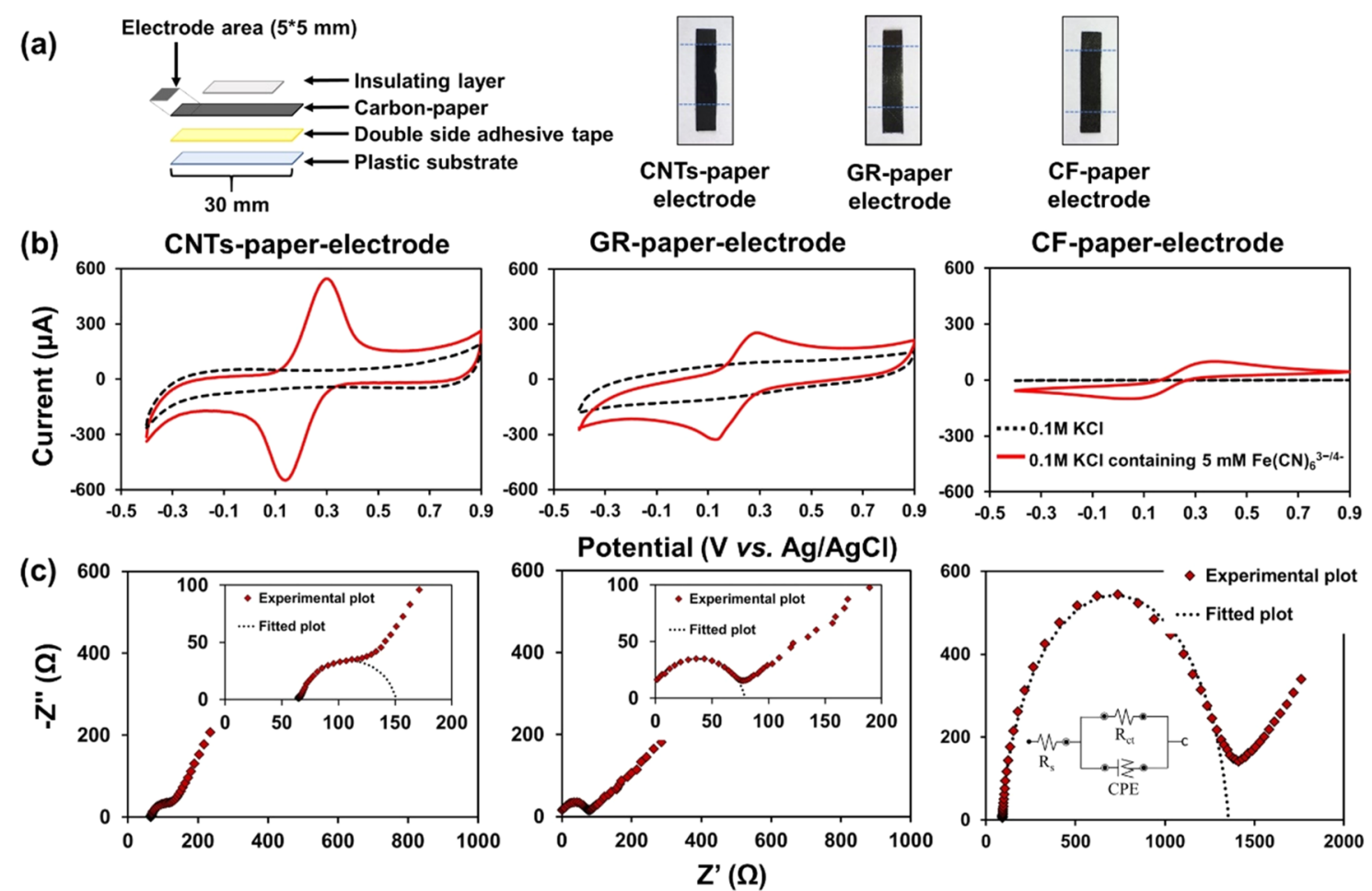

Figure 2. (a) Schematic diagram for the assembling of flexible carbon-paper electrodes and corresponding digital images. (b) Cyclic voltammograms and (c) Nyquist plots of CNTs-paper, GR-paper, and CF-paper in $0.1 \mathrm{M} \mathrm{KCl}$ containing $5 \mathrm{mM}\left[\mathrm{FeCN}_{6}\right]^{3-/ 4-}$.

structural properties for different bare allotropic carbon papers were further investigated by Raman spectroscopy. As shown in Figure 1d, all of the Raman spectra for bare CNTs-paper, GRpaper, and CF-paper exhibit two main characteristic bands that are specific for graphite-like materials with $\mathrm{sp}^{2}$ carbon, including the $\mathrm{G}$ band $\left(\sim 1580 \mathrm{~cm}^{-1}\right)$ and the $2 \mathrm{D}$ band $\left(\sim 2670 \mathrm{~cm}^{-1}\right)$ corresponding to the crystalline ordering of the graphitic basal plane and the stacking order, respectively. ${ }^{39,40}$ In addition, the CNTs-paper and CF-paper also possess another band located at $\sim 1330 \mathrm{~cm}^{-1}$ ( $\mathrm{D}$ band), which is ascribed to the structural disorder and defect or the amorphous carbon material. ${ }^{41}$ The peak position, the intensity ratio of the $\mathrm{D}$ to $\mathrm{G}$ band $\left(I_{\mathrm{D}} / I_{\mathrm{G}}\right)$, and the full width at half-maximum (FWHM) for all of the original allotropic carbon papers are summarized in Table 1 . The $I_{\mathrm{D}} / I_{\mathrm{G}}$ ratio is commonly used for qualitative evaluation of the carbon material. ${ }^{40}$ However, the magnitude of FWHM is related to the orderliness of carbon materials. ${ }^{42}$ For GR-paper, the absence of the $\mathrm{D}$ band and the existence of a sharp G band $\left(\mathrm{FWHM}=13.8 \mathrm{~cm}^{-1}\right)$ indicate that a good graphene structure remained with symmetric bond stretching of all carbon-carbon bonds $\left(\mathrm{sp}^{2}\right)$ in the honeycomb lattice structure. ${ }^{41,43}$ Moreover, the CNTs and CF-papers exhibit a high defect order with $I_{\mathrm{D}} / I_{\mathrm{G}}$ ratios of 0.542 and 0.564 , respectively, implying a higher disorder as well as defects or impurities for CNTs-paper and CF-paper.

Effect on Pretreatment and Electrochemical Properties of the 2D-, Nano-, and Microstructured Allotropic Carbon-Based Paper Electrodes. Physical (oxygen plas$\mathrm{ma})^{37,38}$ and chemical solvents such as nitric acid, ${ }^{44}$ potassium hydroxide, $^{45}$ and isopropanol ${ }^{46}$ are commonly used for pretreatment and activation of electrode materials. For chemical pretreatment, nitric acid and potassium hydroxide act as a strong acid/base, and therefore, isopropanol was used in our study. The electrochemical properties of allotropic carbon-based paper electrodes before and after pretreatments were evaluated by cyclic voltammetry $(\mathrm{CV})$ in $0.1 \mathrm{M} \mathrm{KCl}$ with $2 \mathrm{mM}\left[\mathrm{FeCN}_{6}\right]^{3-/ 4-}$ as the redox probe (Figure S1). For CNTs-paper, the chemical isopropanol pretreatment could realize not only the decrease of background current and elimination of noise peak originating from the impurities during manufacture but also the improvement of electron transfer with a decreased peak-to-peak potential separation $\left(\Delta E_{\mathrm{p}}\right)$ compared to that of nontreated and plasma-treated CNTs-paper. Typically during the CNTs-paper construction, surfactants such as sodium dodecyl sulfate (SDS) or Triton X100 are added to increase the ability of CNT dispersion, 
resulting in hindering the electrical conductivity. Isopropanol has the ability of removing residual surfactants that are retained on the surface of the carbon-paper material during the fabrication process. $^{31}$ For GR-paper, the plasma treatment achieved the best electrochemical performance for $[\mathrm{Fe}$ $\left.(\mathrm{CN})_{6}\right]^{3-/ 4-}$ with a sharper redox due to the introduction of oxygen-rich functional groups with enhanced electrode activities and increased surface hydrophilicity ${ }^{47}$ (Figure S2). On the contrary, there is no significant contribution from the pretreatment for CF-paper. Therefore, isopropanol treatment, plasma treatment, and nontreatment were chosen as optimized pretreatment conditions for CNTs-paper, GR-paper, and CFpaper, respectively, for further experiments and referred to as pretreated carbon papers in the following sections.

The morphology of carbon-based paper electrodes after pretreatment (isopropanol pretreatment for CNTs-paper and CF-paper, plasma pretreatment for GR-paper) was examined using SEM. Based on the SEM images, the morphologies of all of the carbon-based paper electrodes after pretreatment were similar to those before pretreatment (Figure S3). Therefore, pretreatment had no effect on the morphology of carbon-based paper electrodes.

Raman spectroscopy was used to evaluate the pretreatment effect with the optimized pretreatment conditions for the allotropic carbon papers (Figure 1e). All of the allotropic carbon-based papers show typical characteristic D-bands, Gbands, and 2D bands similar to laser-induced graphene (LIG) and GR materials as reported ${ }^{48-50}$ (Table S1). After treatment with isopropanol, the $I_{\mathrm{D}} / I_{\mathrm{G}}$ ratio of CNTs-paper increased from 0.54 to 0.64 and the FWHM value of the $G$ band increased from 37.4 to 40.4 , indicating the increase of structural defects on the surface of CNTs-paper (Table 1). Such structural defects on CNTs are favorable for the enhanced electrochemical reaction activity, ${ }^{51}$ which is consistent with the improved electron-transfer effect in $\mathrm{CV}$ (Figure S1c). In the case of GR-paper, the new appearance of the $\mathrm{D}$ band after plasma treatment at $1341 \mathrm{~cm}^{-1}$ and the slight increase of the FWHM value of G from 13.8 to 14.0 can be ascribed to the formation of disorder at graphene due to oxygenated functional groups, ${ }^{52}$ which was further certified by the improved hydrophilicity with the decreased water contact angle from 90.3 to $73.1^{\circ}$ (Figure S2). Such a disorder in graphene is favorable for the improved electrochemical reaction activity, ${ }^{52,53}$ which can be clearly seen from the sharper redox peaks for GR-paper treated with plasma (Figure $\mathrm{S} 1 \mathrm{~b})$. On the other hand, a decreased intensity of characteristic peaks was observed in the case of CF-paper after isopropanol pretreatment. The $I_{\mathrm{D}} / I_{\mathrm{G}}$ ratio decreasing from 0.56 to 0.09 corresponds to an increase in the graphitic crystalline structure over the disorder. ${ }^{54}$

The allotropic carbon-paper-based flexible electrodes were prepared via shaping of the conducting papers into strips followed by assembling the carbon-paper strip with an insulating substrate and an encapsulation layer using adhesive tape (Figure 2a). The electrochemical properties of the resulting carbon-paper electrodes were characterized by $\mathrm{CV}$ in $0.1 \mathrm{M} \mathrm{KCl}$ containing $5 \mathrm{mM}\left[\mathrm{FeCN}_{6}\right]^{3-/ 4-}$. As shown in Figure $2 \mathrm{~b}$, all allotropic carbon-paper-based electrodes demonstrated a pair of reversible redox peaks, revealing a good reversible electrochemical process at the electrode interface. The anodic peak currents for the CNT-, GR-, and CF-paper-based electrodes were 460, 180, and $96 \mu \mathrm{A}$, respectively, in which the anodic peak currents of CNTs- paper were 2.6 and 4.8 times higher than those of GR- and CFpaper-based electrodes. Such an increase in the peak current is likely due to the porous and nanostructured CNT network possessing a higher active electrode surface area. Besides, the CNTs and GR-paper-based electrodes displayed relatively smaller $\Delta E_{\mathrm{p}}$ values of 160 and $150 \mathrm{mV}$, respectively, while the CF-paper-based electrode exhibited the largest $\Delta E_{\mathrm{p}}$ value of $330 \mathrm{mV}$. Moreover, electrochemical kinetics of carbon paper were further investigated by studying the effect of scan rate. The current response increased linearly versus the square root of the scan rate from 0.01 to $0.17 \mathrm{~V} \mathrm{~s}^{-1}$ (Figure S4), suggesting that the electrochemical kinetic process is diffusion-controlled. The apparent diffusion coefficients of the redox probe toward the allotropic carbon-paper-based electrodes were calculated to be $7.53 \times 10^{-5}$ (CNTs-paper), $3.38 \times 10^{-6}$ (GR-paper), and $3.53 \times 10^{-6}$ (CF-paper) $\mathrm{cm} 2 \mathrm{~s}^{-1}$ using the Randles Sevcik equation. Furthermore, CNTs-paper showed better electrochemical characteristics compared to GR-paper due to the interconnected CNT nanofibers with a porous electrode morphology compared with GR-paper with a compacted stacking of the GR nanosheet.

EIS was performed to examine the electron-transfer kinetics of the bare carbon-paper electrodes in the frequency range from $0.01 \mathrm{~Hz}$ to $100 \mathrm{kHz}$ in $0.1 \mathrm{M} \mathrm{KCl}$ containing $5 \mathrm{mM}$ $\left[\mathrm{FeCN}_{6}\right]^{3-/ 4-}$. Figure $2 \mathrm{c}$ shows the corresponding Nyquist plots and the EIS fitting curve for the CNT-, GR-, and CFpaper-based flexible electrodes. The diameter of the semicircle in the fitted curves was used to measure the charge-transfer resistance $\left(R_{\mathrm{ct}}\right)$. The $R_{\mathrm{ct}}$ is used to characterize the kinetics of the redox probe on the surface of the electrode material. ${ }^{55}$ The $R_{\mathrm{ct}}$ values for electrodes based on CNTs-paper $(87.77 \Omega)$ and GR-paper $(87.32 \Omega)$ were much smaller than that of the CFpaper-based electrode $(1,259 \Omega)$. It is worthy to note that the $R_{\mathrm{ct}}$ value of the nanostructured carbon papers (i.e., CNTs and $\mathrm{GR}$ ) was much lower than that of the microstructured carbonpaper (i.e., CF) electrode, which is in agreement with the corresponding electrochemical characteristics measured from $\mathrm{CV}$. Moreover, the similar $R_{\mathrm{ct}}$ values for CNTs-paper and GRpaper can be ascribed to their intrinsic nanostructure property.

Taking the diffusion process into consideration, the heterogeneous electron-transfer-rate constant $\left(k^{\circ}\right)$ was estimated via EIS for the allotropic carbon materials as the following equation ${ }^{56}$

$$
k^{\circ}=\frac{R T}{n^{2} F^{2} A R_{\mathrm{ct}}[\mathrm{S}]}
$$

where $k^{\circ}$ is the heterogeneous electron-transfer rate constant, $A$ is the geometric area of the working electrode $\left(\mathrm{cm}^{2}\right), T$ is the temperature $(\mathrm{K}), n$ is the number of electron transfers per molecule of the redox probe, $R$ is the universal gas constant, $[S]$ is the bulk concentration of the redox probe $\left(\mathrm{mol} \mathrm{cm}^{-3}\right)$, and $R_{\mathrm{ct}}$ is the charge-transfer resistance. The $k^{\circ}$ values for CNTs-, GR-, and CF-paper-based electrodes were calculated to be $2.43 \times 10^{-3}, 2.44 \times 10^{-3}$, and $1.69 \times 10^{-4} \mathrm{~cm} \mathrm{~s}^{-1}$, respectively. The $k^{\circ}$ values of CNTs- and GR-paper-based electrodes were $\sim 14$ times higher than that of the CF-paperbased electrode. It indicates that the nanostructures of CNTs and the uniform packing of GR sheets within the assembled bulk conducting papers preserve the high active surface area and thus promote faster electron-transfer kinetics compared to the CF-paper.

Bending Stability of the 2D-, Nano-, and Microstructured Carbon-Based Flexible Electrodes. To inves- 
tigate the mechanical properties of different allotropic carbon papers as flexible electrodes, the CNTs-, GR-, and CF-paper electrodes were subjected to repeated bending cycles at a $150^{\circ}$ bending angle for 300 cycles (Figure 3 ). The bending stability
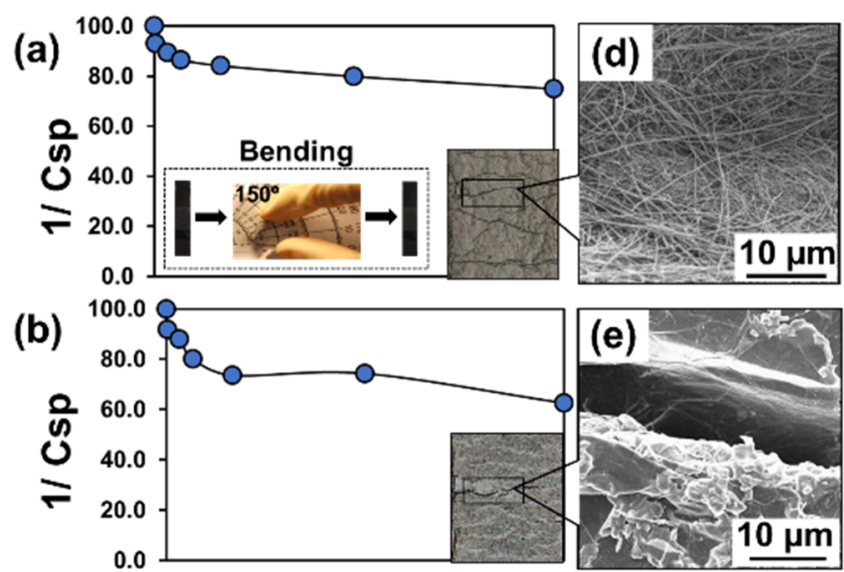

(c)

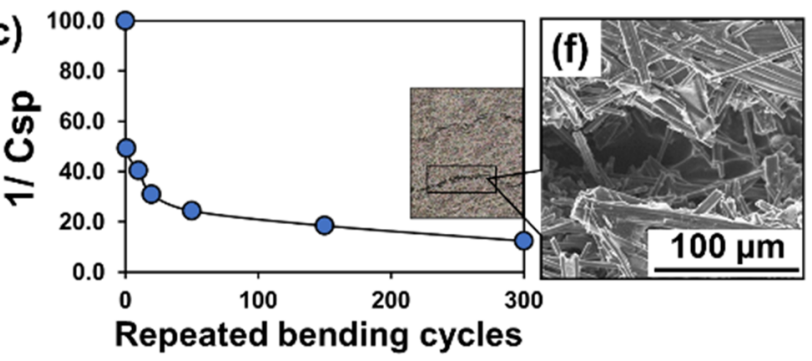

Figure 3. Bending stability test evaluated by $1 / C_{\mathrm{sp}}$ with repeated bending cycles and corresponding SEM images in high magnification after 300 cycles bending for (a) CNTs-paper-, (b) GR-paper-, and (c) CF-paper-based flexible electrodes. (a) Inset shows the bending angle. SEM image in low magnification at bending position for (d) CNTspaper, (e) GR-paper, and (f) CF-paper after repeated 300 bending cycles.

was evaluated based on the hypothesis that structural fracture will create cracks or defects on the surface of the allotropic carbon-based electrodes and consequently increase the appearance of the surface area of the electrodes. The increase in the electrode surface area would enhance ion interaction at the electrode interface, leading to an increase in the areaspecific capacitance. The changes in capacitance were evaluated by $\mathrm{CV}$ scanning at a potential ranging from -0.2 to $0.6 \mathrm{~V}$ at $0.05 \mathrm{~V} \mathrm{~s}^{-1}$ in $0.1 \mathrm{M} \mathrm{KCl}$ solution. The specific capacitance was calculated from CVs according to eq $2.57,58$

$$
C_{\mathrm{sp}}=\frac{1}{m v \Delta v} \int i(v) \mathrm{d} v
$$

where $C_{\mathrm{sp}}$ is the specific capacitance, $m$ is the geometric area of the working electrode $\left(\mathrm{cm}^{2}\right), v$ is the scan rate, $\Delta v$ is the potential window, and $\int i(v) \mathrm{d} v$ is the area under the CV curve. The apparent bending stability caused by the cracks and defects is thus inversely proportional to the change in capacitance, and therefore can be defined as $1 / C_{\mathrm{sp}}$. The apparent bending stability of different allotropic carbon-based electrodes as a function of bending cycles is shown in Figure $3 a-c$, whereas the initial capacitance before bending was normalized as $100 \%$. The result shows that after an initial 10 bending cycles, the $1 / C_{\mathrm{sp}}$ values of CNTs-, GR-, and CF-paper electrodes dropped to $89.4,88.0$, and $40.5 \%$ (i.e., decreases of
10.6, 12.0, and 59.5\%), respectively. The obtained bending stabilities of the CNTs-paper and GR-paper electrodes were 5.61 and 4.96 times better in comparison to the CF-paper. However, after 20 bending cycles, the $1 / C_{\mathrm{sp}}$ values of CNTspaper, GR-paper, and CF-papers showed smaller decreases of 2.9, 7.9, and 9.6\%, respectively. Interestingly, after a high number of continuous bending for 150 cycles, the impact on $1 / C_{\text {sp }}$ values of the CNTs-paper, GR-paper, and CF-paper resulting from the bending is significantly further reduced with only small decreases of $6.6,5.8$, and $12.4 \%$, respectively. According to the thickness measurements by SEM (Figure 1c), despite the CF-paper being the thinnest carbon substrate, it has the lowest bending stability compared with CNTs- and GR-paper. However, carbon papers composed of nanostructured materials provide better bending stability, which is likely due to the nanodimensional feature of the assembled CNTs and GR being more resistant to structural fracture upon bending. The SEM images of the CNTs-, GR-, and CF-paper electrodes after 300 bending cycles are shown in Figure $3 \mathrm{~d}-\mathrm{f}$. The surface of the CNTs-paper showed a few wrinkles and the GR-paper showed creases, while the CF-paper had a fractured and broken fiber structure around the bending site. The morphologies of the bent carbon papers agreed with the corresponding results obtained from the $1 / C_{s p}$ measurement. More interestingly, we observed that the initial bending cycles created a larger impact on the stability of all of the carbon papers, followed by a relatively more stable value after the initial bending cycles. This observation could be explained by the classical properties and characteristics of paper substrates-that defects were created upon initial bending while remaining fairly stable upon rebending. The magnitude of the defects associated with the bending stability is highly related to the structure and organization of the allotropic carbon materials' packed-paper format. Additionally, the bending stability of different allotropic carbon papers was evaluated by $\mathrm{CV}$ using a $\left[\mathrm{FeCN}_{6}\right]^{3-/ 4-}$ redox probe (Figure $\mathrm{S} 5$ ). After 300 bending cycles, the oxidation peak currents measured by the CNTs-, GR-, and CF-papers were increased by 42.8, 45.7, and $94.5 \%$, respectively. The increased peak current is likely due to the cracks or defects on the surface of the allotropic carbon-based electrodes with an increased appearance of the surface area of the electrodes. Both capacitive and chargetransfer characterizations indicate that the CNTs-paper and GR-paper electrodes have a better bending stability compared with the CF-paper electrode.

PB-Functionalized Allotropic Carbon-Paper Electrodes (PB-Carbon-Paper) for Electrochemical Sensing. For advanced electronic devices, modification of the electrodes with inorganic catalysts or organic conducting polymers is essential. Carbon-based papers were activated by appropriate pretreatment before being functionalized with inorganic catalysts or organic conducting polymers. To explore the postmodification performance of conducting carbon papers for electrochemical sensing application, a commonly used inorganic catalyst $\mathrm{PB}$ was electrochemically deposited onto different carbon-paper electrodes for the preparation of $\mathrm{PB}$ carbon-paper electrodes for hydrogen peroxide $\left(\mathrm{H}_{2} \mathrm{O}_{2}\right)$ detection, which is an important analyte in the biological system that is generated from reactions catalyzed by oxidases. ${ }^{59}$ The morphology and chemical characteristics of the PBmodified carbon-paper electrodes were evaluated by SEM and energy-dispersive X-ray analysis (EDX). The SEM images showed the deposition of granulated PB particles onto CNTs- 
(a)
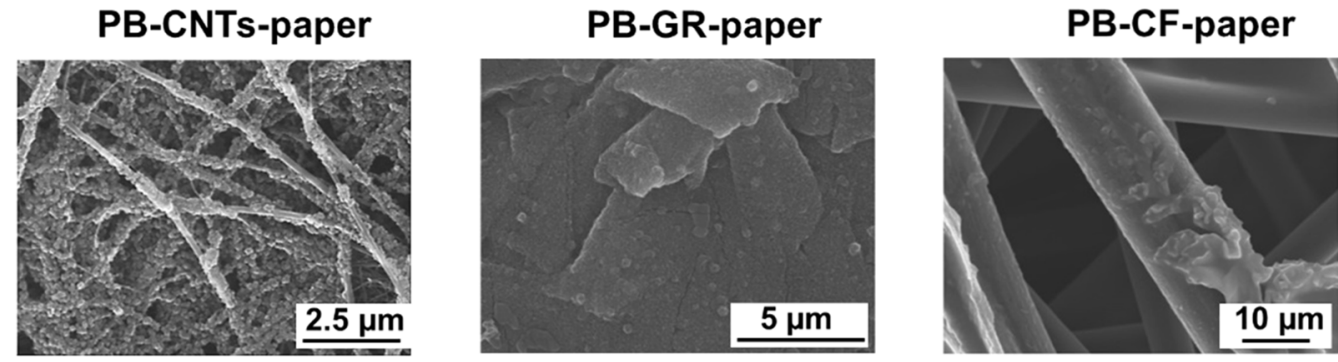

(b)
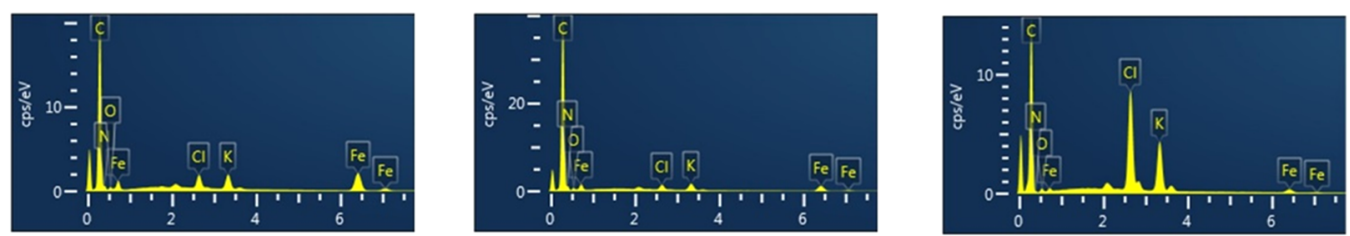

(c)
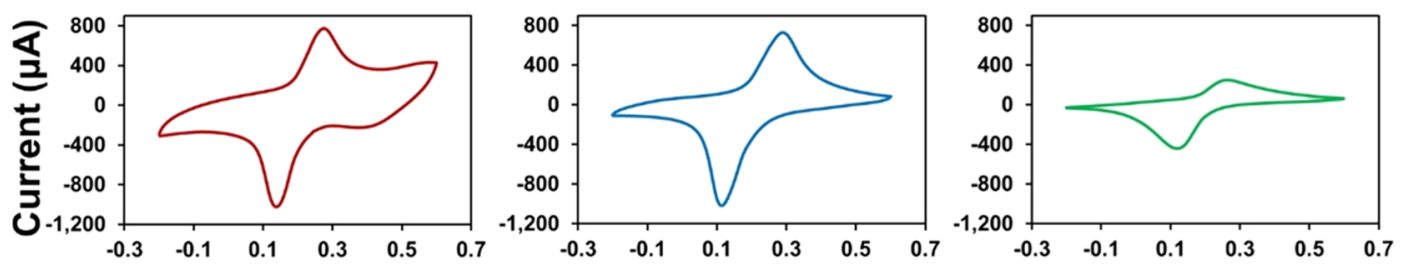

(d)

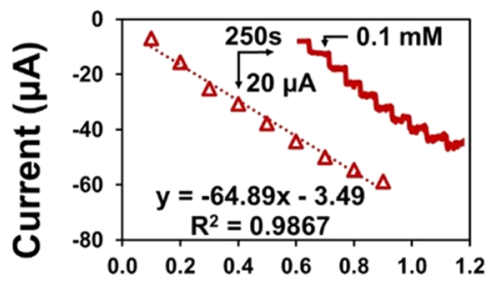

Potential (V vs. Ag/AgCl)
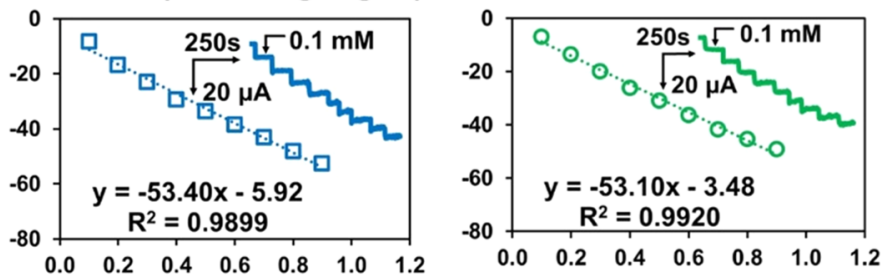

\section{Concentration of $\mathrm{H}_{2} \mathrm{O}_{2}(\mathrm{mM})$}

Figure 4. (a) SEM images and (b) EDX spectra of PB-CNTs-paper, PB-GR-paper, and PB-CF-paper. (c) Cyclic voltammograms of PB-CNTspaper, PB-GR-paper, and PB-CF-paper in $0.1 \mathrm{M} \mathrm{KCl}$ solution containing $0.01 \mathrm{M} \mathrm{HCl}$. (d) Calibration curves of electrochemical sensing of $\mathrm{H}_{2} \mathrm{O}_{2}$ at PB-CNTs-paper, PB-GR-paper, and PB-CF-paper; insets show the corresponding current-time curve at a working potential of $0.0 \mathrm{~V}$ in $0.1 \mathrm{M}$ PBS ( $\mathrm{pH}$ 6.0).

paper, GR-paper, and CF-paper (Figure 4a). The EDX spectra illustrate the presence of the characteristic elements, i.e., iron $(\mathrm{Fe})$ and nitrogen $(\mathrm{N})$, originating from the $\mathrm{PB}$, indicating the successful preparation of PB-CNTs-paper, PB-GR-paper, and PB-CF-paper electrodes (Figure 4b). The electrochemical properties of the $\mathrm{PB}$-modified carbon-paper electrodes were characterized by $\mathrm{CV}$ showing a typical pair of quasi-reversible peaks resulting from the redox behavior of $\mathrm{Fe}^{3+} / \mathrm{Fe}^{2+}$ in $\mathrm{PB}$ (Figure 4c). The CVs of the PB-CNTs-, PB-GR-, and PB-CFpapers showed a pair of characteristic peaks of $\mathrm{PB} .{ }^{60}$ The cathodic peak currents of the PB-CNTs- and PB-GR-paper electrodes were higher $(\sim 1.8$ and $\sim 2.2$ times $)$ compared with that of the PB-CF-paper electrode. This indicates that a higher amount of PB deposited onto the CNTs- and GR-paper electrodes related to the relatively dense electrode surface morphology compared with the CF-paper electrode, as shown in the SEM image (Figure 4a). Moreover, the PB-CNTs- and PB-GR-paper electrodes exhibit a significantly sharper redox peak compared with the PB-CF-paper electrode. The sharpness of the $\mathrm{PB}$ redox peaks represents the inorganic polycrystalline structure on carbonaceous materials and was used to evaluate the quality of $\mathrm{PB} .{ }^{61,62}$ Figure $4 \mathrm{~d}$ (insets) shows the current-time responses measured at $0 \mathrm{~V}$ with the successive addition of $\mathrm{H}_{2} \mathrm{O}_{2}$ for PB-CNTs-, PB-GR-, and PB-
CF-paper electrodes with a fast response time that reaches a steady-state current within 10-20 s. All of the PB-modified carbon-paper electrodes exhibited a good linear relationship in the concentration range of $0.1-0.9 \mathrm{mM}$ with a correlation coefficient $>0.99$ (Figure 4d). Among all, the PB-CNTs-paper electrode showed the highest sensitivity of $64.89 \mu \mathrm{A} \mathrm{mM}{ }^{-1}$, while the PB-GR-paper and PB-CF-paper electrodes also presented good sensitivities of 53.40 and $53.10 \mu \mathrm{A} \mathrm{mM}{ }^{-1}$, respectively. The assembled CNT-paper electrode with an interconnected nanofibrous structure with a porous electrode morphology compared with the compacted GR-paper electrode (Figure 4a) with a large appearance of surface area facilitates the deposition of $\mathrm{PB}$, resulting in better electrochemical and sensing performances. The analytical performances of the PB-modified carbon-paper electrodes for $\mathrm{H}_{2} \mathrm{O}_{2}$ detection have been compared with other reports, as shown in Table S2. Compared to other reports, the PB-modified carbonbased paper exhibited a high sensitivity with low potential detection. As such, the carbon-based papers could be an alternative substrate for the application of sensors/biosensors.

PEDOT-Functionalized Allotropic Carbon-Paper Electrodes (PEDOT-Carbon-Paper) for Charge Storage. To evaluate the electrochemical energy storage applications, supercapacitive electrodes were fabricated by electrodeposition 
(a)

PEDOT-CNTs-paper

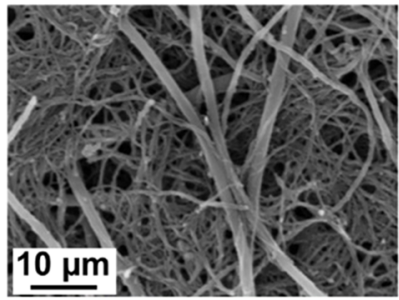

(b)

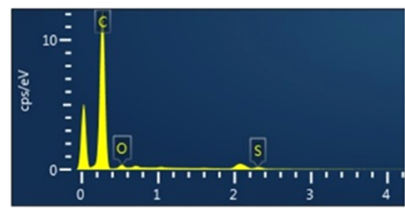

(c)

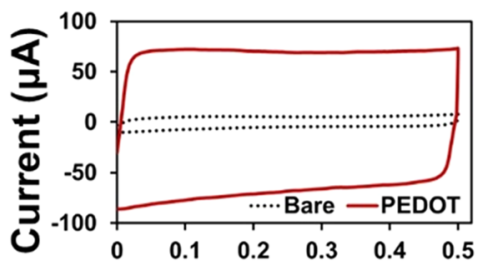

(d)

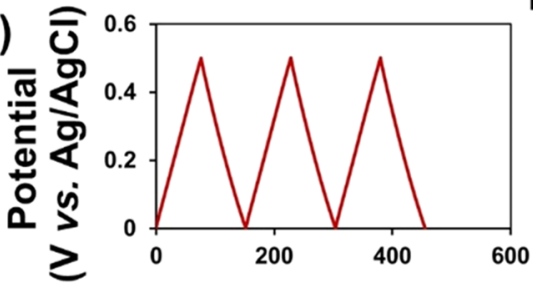

PEDOT-GR-paper
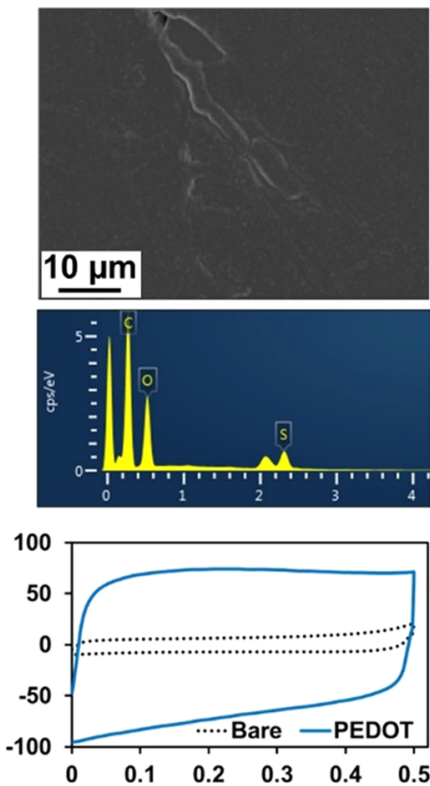

Potential (V vs. $\mathrm{Ag} / \mathrm{AgCl})$

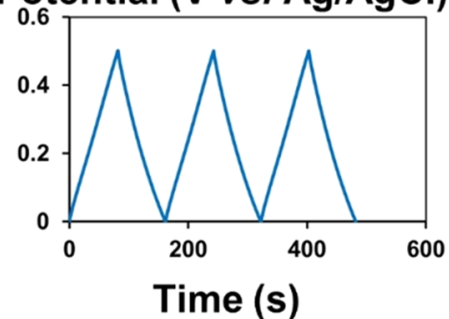

PEDOT-CF-paper
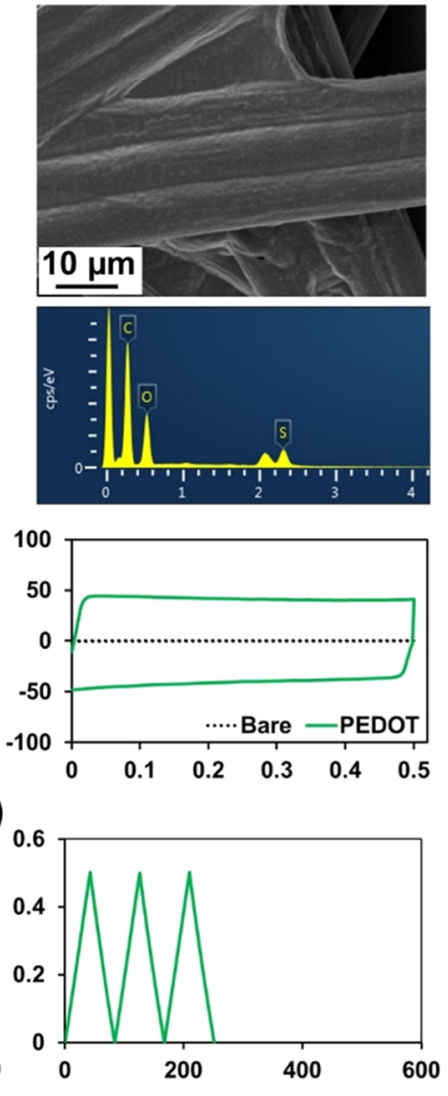

Figure 5. (a) SEM images and (b) EDX spectra of PEDOT-CNTs-paper, PEDOT-GR-paper, and PEDOT-CF-paper. (c) Cyclic voltammograms of CNTs-paper, GR-paper, and CF-paper in $0.1 \mathrm{M} \mathrm{KCl}$ solution before and after modification of PEDOT at a scan rate of $0.05 \mathrm{~V} \mathrm{~s}{ }^{-1}$. (d) Galvanostatic charge-discharge curves of PEDOT-CNTs-paper, PEDOT-GR-paper, and PEDOT-CF-paper in $0.1 \mathrm{M} \mathrm{KCl} \mathrm{solution.}$

of PEDOT onto different allotropic carbon-paper electrodes, in which PEDOT is a pseudocapacitive material having a high specific capacitance and ionic conductivity. ${ }^{63,64}$ The morphology and chemical characteristic of the PEDOT-carbon-paper electrode were characterized by SEM and EDX analyses. A PEDOT film was electrochemically deposited onto the CNTs-, GR-, and CF-paper electrodes (Figure 5a). The EDX spectra showed that the typical sulfur $(\mathrm{S})$ and oxygen $(\mathrm{O})$ elements originating from the PEDOT indicate the successful preparation of PEDOT-CNTs-paper, PEDOT-GR-paper, and PEDOT-CF-paper electrodes (Figure 5b). The electrocapacitive performance of the PEDOT-carbon-paper electrodes was evaluated with cyclic voltammetry (CV) and galvanostatic charge-discharge (GCD) measurement in $0.1 \mathrm{M} \mathrm{KCl}$ solution. Figure $5 \mathrm{c}$ shows the typical symmetric rectangular-shaped $\mathrm{CV}$ curves resulting from the electrochemical pseudocapacitive properties of PEDOT. The GCD curves (Figure 5d) obtained from all of the PEDOT-carbon-paper electrodes showed a symmetric triangular-shaped curve illustrating the typical electrocapacitive behavior of the electrodes. The PEDOTCNTs-paper electrode and the PEDOT-GR-paper electrode showed slower discharge kinetics (i.e., longer times of charge or discharge) in comparison with the PEDOT-CF-paper electrode with the same geometric electrode surface area, which is likely contributed by the nanostructural feature of the CNTs and GR with a higher surface area leading to a longer charging/discharging time. The specific capacitance $\left(C_{\mathrm{sp}}\right)$ representing the charge storage ability of the PEDOT-modified carbon-paper electrodes was calculated from discharge slopes at various current densities according to eq $3^{65}$

$$
C_{\mathrm{sp}}=\frac{i \times t}{\Delta v}
$$

where $i$ is the current density $\left(\mathrm{A} \mathrm{cm}{ }^{-2}\right), t$ is the charge/ discharge time (s), and $\Delta v$ is the electrochemical potential window $(\mathrm{V})$. The calculated $C_{\mathrm{sp}}$ values for the PEDOT-CNTspaper, PEDOT-GR-paper, and PEDOT-CF-paper electrodes were $12.34,12.49$, and $6.86 \mathrm{mF} \mathrm{cm}^{-2}$, respectively. This result is consistent with the $\mathrm{CV}$ measurement showing a similar trend on the electrochemical pseudocapacitive behavior related to the size of the rectangular-shaped CV curves. This result demonstrates the effective modification of all carbon-paper electrodes with PEDOT for charge storage. However, the PEDOT-CNTs-paper and PEDOT-GR-paper composed of nanostructured carbon materials showed a significantly higher $C_{\text {sp }}$ compared with the PEDOT-CF-paper electrode. The capacitance values of the PEDOT-functionalized carbon-based paper electrodes were compared with the literature-reported PEDOT-modified electrodes, showing comparable and in some cases higher capacitance values (Table S3), likely attributed to the intrinsic nano-/microstructure within the allotrope carbon-paper substrates with a higher active surface area. 
Table 2. Summary of the Evaluation on Physioelectrochemical Properties of Allotropic Carbon-Based Conducting Paper as Flexible Electrodes

\begin{tabular}{|c|c|c|c|c|}
\hline & parameters & CNTs-paper & GR-paper & CF-paper \\
\hline \multirow[t]{4}{*}{ structure properties } & morphology & porous nanofibrous network & multilayer nanosheet assembly & $\begin{array}{l}\text { porous microfibrous } \\
\text { network }\end{array}$ \\
\hline & carbon structure ( $\mathrm{G}$ band) & good $\mathrm{SP}_{2}$ crystalline structure & $\begin{array}{l}\text { excellent } \mathrm{SP}_{2} \text { crystalline } \\
\text { structure }\end{array}$ & $\begin{array}{l}\text { good } \mathrm{SP}_{2} \text { crystalline } \\
\text { structure }\end{array}$ \\
\hline & carbon structure ( $\mathrm{D}$ band) & high defects & na & moderate defects \\
\hline & activation & $\begin{array}{l}\text { enhanced defects by isopropanol } \\
\text { treatment }\end{array}$ & $\begin{array}{l}\text { introduced defects by plasma } \\
\text { treatment }\end{array}$ & no improvement \\
\hline \multirow{3}{*}{$\begin{array}{l}\text { electrochemical } \\
\text { properties }\end{array}$} & electrode kinetic, $\Delta E_{\mathrm{p}}(\mathrm{mV})$ & fast $(160 \mathrm{mV})$ & fast $(150 \mathrm{mV})$ & slow $(330 \mathrm{mV})$ \\
\hline & charge-transfer resistance, $R_{\mathrm{ct}}(\Omega)$ & small $(87.77 \Omega)$ & small $(87.32 \Omega)$ & large $(1259 \Omega)$ \\
\hline & $\begin{array}{l}\text { heterogeneous electron-transfer rate } \\
\text { constant, } k^{\circ}\left(\mathrm{cm}^{-1}\right)\end{array}$ & fast $\left(2.43 \times 10^{-3} \mathrm{~cm}^{-1}\right)$ & fast $\left(2.44 \times 10^{-3} \mathrm{~cm}^{-1}\right)$ & slow $\left(1.69 \times 10^{-4} \mathrm{~cm}^{-1}\right)$ \\
\hline \multirow[t]{2}{*}{ bending stability } & initial 20 bending cycles & good $(86.5 \%$ retain $)$ & good $(80.1 \%$ retain $)$ & poor $(30.9 \%$ retain $)$ \\
\hline & from 20 to 300 cycles & excellent (75\% retain) & good $(62 \%$ retain $)$ & poor $(12.5 \%$ retain $)$ \\
\hline
\end{tabular}

Physicoelectrochemical Properties of 2D-, Nano-, and Microstructured Carbon-Based Paper as Flexible Electrodes. The evaluation of the physicoelectrochemical properties for various allotropic carbon papers as flexible electrodes is summarized in Table 2. The nano and micro features of the CNTs, GR, and CF were retained after the allotropic carbon was compressed into paper sheets. All allotropic carbon papers show a good characteristic $G$ band corresponding to the in-plane vibrations of the $\mathrm{SP}_{2}$ bonded carbon, which is essential as a conducting electrode substrate, while structural defects for the CNTs and GR-papers characterized by the $\mathrm{D}$ band could be enhanced via physical or chemical treatment to deliver an improved electrochemical reaction activity at the electrode interfaces. The nanostructured CNTs- and GR-paper electrodes delivered faster electrode kinetics, low $R_{\mathrm{c}}$, and high $k^{\circ}$ values compared with the microstructured CF-paper. Moreover, the bending stability of the CNTs- and GR-paper electrodes composed of nanostructured carbon showed a significantly higher stability facilitated by the nanodimensional feature of the assembled CNTs and GR for a better resistance on structural fracture upon bending. Despite the price of the CNTs- and GR-papers being higher compared with the CF-paper, their good electrochemical performance and high bending stability are essential for the development of advanced flexible and wearable electronics.

\section{CONCLUSIONS}

The physicochemical properties and electrochemical performance for various allotropic carbon papers as flexible electrodes were studied. All allotropic carbon papers showed a good characteristic $\mathrm{G}$ band corresponding to the in-plane vibrations of $\mathrm{SP}_{2}$ bonded carbon, which is essential as a conducting electrode substrate, while structural defects for the CNTs- and GR-papers characterized by the D band could be enhanced via physical or chemical treatment to deliver an improved electrochemical reaction activity at the electrode interfaces. The nanostructured CNTs- and GR-paper electrodes delivered faster electrode kinetics, lower $R_{\mathrm{ct}}$ and higher $k^{\circ}$ values compared with the microstructured CF-paper. Moreover, the bending stabilities of the CNTs- and GR-paper electrodes composed of nanostructured carbon showed a significantly higher stability facilitated by the nanodimensional feature of the assembled CNTs and GR for a better resistance on structural fracture upon bending. We further demonstrated the functionalization of the allotropic carbon papers with an inorganic catalyst to fabricate PB-carbon-paper for electrochemical sensing and an organic conducting polymer to fabricate PEDOT-carbon-paper for energy storage. Carbonbased conducting papers provide a new route for the design and fabrication of advanced flexible electronic devices. Our studies provide comprehensive studies on the fundamental physioelectrochemical characteristics of allotropic nano-/ microstructured carbon papers, which is critical for the future development of advanced paper-based flexible electronic devices.

\section{ASSOCIATED CONTENT}

\section{Supporting Information}

The Supporting Information is available free of charge at https://pubs.acs.org/doi/10.1021/acs.langmuir.1c02121.

Details of the pretreatment effect using CV and SEM of allotropic carbon papers, contact-angle measurement, effect of scan rate; table showing the Raman spectroscopy parameters of allotropic carbon-based papers compared with other carbon-based materials, and comparison of the performance of $\mathrm{H}_{2} \mathrm{O}_{2}$ sensors and specific capacitance of different PEDOT-modified electrodes (PDF)

\section{AUTHOR INFORMATION}

\section{Corresponding Author}

Wing Cheung Mak - Biosensors and Bioelectronics Centre, Division of Sensor and Actuator Systems, Department of Physics, Chemistry and Biology, Linköping University, SE58183 Linköping, Sweden; (1) orcid.org/0000-0003-32746029; Email: wing.cheung.mak@liu.se

\section{Authors}

Supatinee Kongkaew - Biosensors and Bioelectronics Centre, Division of Sensor and Actuator Systems, Department of Physics, Chemistry and Biology, Linköping University, SE58183 Linköping, Sweden; Center of Excellence for Trace Analysis and Biosensor, Prince of Songkla University, Hat Yai, Songkhla 90110, Thailand; Center of Excellence for Innovation in Chemistry, Faculty of Science and Division of Physical Science, Faculty of Science, Prince of Songkla University, Hat Yai, Songkhla 90110, Thailand

Lingyin Meng - Biosensors and Bioelectronics Centre, Division of Sensor and Actuator Systems, Department of Physics, Chemistry and Biology, Linköping University, SE-581 83 Linköping, Sweden 
Warakorn Limbut - Center of Excellence for Trace Analysis and Biosensor, Prince of Songkla University, Hat Yai, Songkhla 90110, Thailand; Center of Excellence for Innovation in Chemistry, Faculty of Science and Division of Health and Applied Sciences, Faculty of Science, Prince of Songkla University, Hat Yai, Songkhla 90110, Thailand

Proespichaya Kanatharana - Center of Excellence for Trace Analysis and Biosensor, Prince of Songkla University, Hat Yai, Songkhla 90110, Thailand; Center of Excellence for Innovation in Chemistry, Faculty of Science and Division of Physical Science, Faculty of Science, Prince of Songkla University, Hat Yai, Songkhla 90110, Thailand

Panote Thavarungkul - Center of Excellence for Trace Analysis and Biosensor, Prince of Songkla University, Hat Yai, Songkhla 90110, Thailand; Center of Excellence for Innovation in Chemistry, Faculty of Science and Division of Physical Science, Faculty of Science, Prince of Songkla University, Hat Yai, Songkhla 90110, Thailand; (1) orcid.org/0000-0002-6096-6371

Complete contact information is available at: https://pubs.acs.org/10.1021/acs.langmuir.1c02121

\section{Notes}

The authors declare no competing financial interest.

\section{ACKNOWLEDGMENTS}

The authors would like to acknowledge the Swedish Research Council (VR-2015-04434) for financial support to conduct the research. The authors would like to acknowledge the financial support for S.K. from the Royal Golden Jubilee Ph.D. program (RGJ) from the Thailand Research Fund (PHD/0212/2560) to support her research study.

\section{REFERENCES}

(1) Meng, L.; Turner, A. P. F.; Mak, W. C. Soft and flexible materialbased affinity sensors. Biotechnol. Adv. 2020, 39, No. 107398.

(2) Dahiya, A. S.; Shakthivel, D.; Kumaresan, Y.; Zumeit, A.; Christou, A.; Dahiya, R. High-performance printed electronics based on inorganic semiconducting nano to chip scale structures. Nano Convergence 2020, 7, No. 33.

(3) Jiang, Z.; Chen, J. J.; Wang, Y.; Xu, Z.; Sowade, E.; Baumann, R. R.; Sheremet, E.; Rodriguez, R. D.; Feng, Z.; et al. All-Inkjet-Printed Mos2 Field-Effect Transistors on Paper for Low-Cost and Flexible Electronics. Appl. Nanosci. 2020, 10, 3649-3658.

(4) Khan, S.; Lorenzelli, L.; Dahiya, R. S. Technologies for Printing Sensors and Electronics over Large Flexible Substrates: A Review. IEEE Sens. J. 2015, 15, 3164-3185.

(5) Tortorich, R. P.; Shamkhalichenar, H.; Choi, J. W. Inkjet-Printed and Paper-Based Electrochemical Sensors. Appl. Sci. 2018, 8, No. 288.

(6) Omar, M. H.; Razak, K. A.; Ab Wahab, M. N.; Hamzah, H. H. Recent Progress of Conductive 3d-Printed Electrodes Based Upon Polymers/Carbon Nanomaterials Using a Fused Deposition Modelling (Fdm) Method as Emerging Electrochemical Sensing Devices. RSC Adv. 2021, 11, 16557-16571.

(7) David, I. G.; Popa, D. E.; Buleandra, M. Pencil Graphite Electrodes: A Versatile Tool in Electroanalysis. J. Anal. Methods Chem. 2017, 2017, No. 1905968.

(8) de Araujo, W. R.; Frasson, C. M. R.; Ameku, W. A.; Silva, J. R.; Angnes, L.; Paixão, T. R. L. C. Single-Step Reagentless Laser Scribing Fabrication of Electrochemical Paper-Based Analytical Devices. Angew. Chem., Int. Ed. 2017, 56, 15113-15117.

(9) Zhang, C.; Peng, Z.; Huang, C.; Zhang, B.; Xing, C.; Chen, H.; Cheng, H.; Wang, J.; Tang, S. High-Energy All-in-One Stretchable Micro-Supercapacitor Arrays Based on 3d Laser-Induced Graphene
Foams Decorated with Mesoporous Znp Nanosheets for Self-Powered Stretchable Systems. Nano Energy 2021, 81, No. 105609.

(10) Chen, H.; Muller, M. B.; Gilmore, K. J.; Wallace, G. G.; Li, D. W. Mechanically Strong, Electrically Conductive, and Biocompatible Graphene Paper. Adv. Mater. 2008, 20, 3557-3561.

(11) Xiao, F.; Li, Y.; Zan, X.; Liao, K.; Xu, R.; Duan, H. Growth of Metal-Metal Oxide Nanostructures on Freestanding Graphene Paper for Flexible Biosensors. Adv. Funct. Mater. 2012, 22, 2487-2494.

(12) Hu, L.; Kim, H. S.; Lee, J. Y.; Peumans, P.; Cui, Y. Scalable Coating and Properties of Transparent, Flexible, Silver Nanowire Electrodes. ACS Nano 2010, 4, 2955-2963.

(13) Yang, L.; Zhou, W.; Jia, J.; Xiong, T.; Zhou, K.; Feng, C.; Zhou, J.; Tang, Z.; Chen, S. Nickel Nanoparticles Partially Embedded into Carbon Fiber Cloth Via Metal-Mediated Pitting Process as Flexible and Efficient Electrodes for Hydrogen Evolution Reactions. Carbon 2017, 122, 710-717.

(14) Kim, S.; Yun, T. G.; Kang, C.; Son, M. J.; Kang, J. G.; Kim, I. H.; Lee, H. J.; An, C. H.; Hwang, B. Facile Fabrication of Paper-Based Silver Nanostructure Electrodes for Flexible Printed Energy Storage System. Mater. Des. 2018, 151, 1-7.

(15) Cheng, T.; Zhang, Y.; Zhang, J. Z.; Lai, W. Y.; Huang, W. HighPerformance Free-Standing Pedot:Pss Electrodes for Flexible and Transparent All-Solid-State Supercapacitors. J. Mater. Chem. A 2016, 4, 10493-10499.

(16) Wang, H.; Zhang, D.; Yan, T.; Wen, X.; Zhang, J.; Shi, L.; Zhong, Q. Three-Dimensional Macroporous Graphene Architectures as High Performance Electrodes for Capacitive Deionization. J. Mater. Chem. A 2013, 1, 11778-11789.

(17) Zou, Y.; Wang, S. Interconnecting Carbon Fibers with the inSitu Electrochemically Exfoliated Graphene as Advanced Binder-Free Electrode Materials for Flexible Supercapacitor. Sci. Rep. 2015, 5, No. 11792.

(18) Pushparaj, V. L.; Shaijumon, M. M.; Kumar, A.; Murugesan, S.; Ci, L.; Vajtai, R.; Linhardt, R.; Nalamasu, O.; Ajayan, P. M. Flexible Energy Storage Devices Based on Nanocomposite Paper. Proc. Natl. Acad. Sci. U.S.A. 2007, 104, 13574-13577.

(19) Zhao, W.; Zhang, M.; Pan, P.; Song, D.; Huang, S.; Wei, J.; Li, X.; Qi, W.; Zhang, K.; Zhao, J.; Yang, Z. Design and Fabrication of Flexible Supercapacitor Devices by Using Mesoporous Carbon/ Polyaniline Ink. Surf. Coat. Technol. 2017, 320, 595-600.

(20) Meng, L.; Turner, A. P. F.; Mak, W. C. Tunable 3d Nanofibrous and Bio-Functionalised Pedot Network Explored as a Conducting Polymer-Based Biosensor. Biosens. Bioelectron. 2020, 159, No. 112181.

(21) Uzunçar, S. M.; Meng, L.; Turner, A. P. F.; Mak, W. C. Processable and Nanofibrous Polyaniline:Polystyrene-Sulphonate (Nano-Pani:Pss) for the Fabrication of Catalyst-Free Ammonium Sensors and Enzyme-Coupled Urea Biosensors. Biosens. Bioelectron. 2021, 171, No. 112725.

(22) Meng, L.; Turner, A. P. F.; Mak, W. C. Positively-Charged Hierarchical Pedot Interface with Enhanced Electrode Kinetics for Nadh-Based Biosensors. Biosens. Bioelectron. 2018, 120, 115-121.

(23) Li, Z.; Ma, G.; Ge, R.; Qin, F.; Dong, X.; Meng, W.; Liu, T.; Tong, J.; Jiang, F.; Zhou, Y.; Li, K.; Min, X.; Huo, K.; Zhou, Y. FreeStanding Conducting Polymer Films for High-Performance Energy Devices. Angew. Chem., Int. Ed. 2016, 55, 979-982.

(24) Yu, G.; Xie, X.; Pan, L.; Bao, Z.; Cui, Y. Hybrid Nanostructured Materials for High-Performance Electrochemical Capacitors. Nano Energy 2013, 2, 213-234.

(25) Pereira, A. R.; de Souza, J. C. P.; Iost, R. M.; Sales, F.; Crespilho, F. N. Application of Carbon Fibers to Flexible Enzyme Electrodes. J. Electroanal. Chem. 2016, 780, 396-406.

(26) Yang, C.; Denno, M. E.; Pyakurel, P.; Venton, B. J. Recent Trends in Carbon Nanomaterial-Based Electrochemical Sensors for Biomolecules: A Review. Anal. Chim. Acta 2015, 887, 17-37.

(27) He, W.; Sun, Y.; Xi, J.; Abdurhman, A. A. M.; Ren, J.; Duan, H. Printing Graphene-Carbon Nanotube-Ionic Liquid Gel on Graphene Paper: Towards Flexible Electrodes with Efficient Loading of Ptau 
Alloy Nanoparticles for Electrochemical Sensing of Blood Glucose. Anal. Chim. Acta 2016, 903, 61-68.

(28) Xiao, F.; Song, J.; Gao, H.; Zan, X.; Xu, R.; Duan, H. Coating Graphene Paper with 2d-Assembly of Electrocatalytic Nanoparticles: A Modular Approach toward High-Performance Flexible Electrodes. ACS Nano 2012, 6, 100-110.

(29) Torres-Mendieta, R.; Ventura-Espinosa, D.; Sabater, S.; Lancis, J.; Mínguez-Vega, G.; Mata, J. A. In Situ Decoration of Graphene Sheets with Gold Nanoparticles Synthetized by Pulsed Laser Ablation in Liquids. Sci. Rep. 2016, 6, No. 30478.

(30) Baig, N.; Sajid, M.; Saleh, T. A. Recent Trends in Nanomaterial-Modified Electrodes for Electroanalytical Applications. TrAC, Trends Anal. Chem. 2019, 111, 47-61.

(31) He, J.; Guo, C.; Zhou, S.; Zhao, Y.; Wang, Q.; Yang, J.; Yang, S.; Wang, Q. Dual Carbon-Modified Nickel Sulfide Composites toward High-Performance Electrodes for Supercapacitors. Inorg. Chem. Front. 2019, 6, 226-232.

(32) Scotto, J.; Piccinini, E.; Bilderling, C.; Coria-Oriundo, L. L.; Battaglini, F.; Knoll, W.; Marmisolle, W. A.; Azzaroni, O. Flexible Conducting Platforms Based on Pedot and Graphite Nanosheets for Electrochemical Biosensing Applications. Appl. Surf. Sci. 2020, 525, No. 146440.

(33) Wang, Z.; Han, Y.; Zeng, Y.; Qie, Y.; Wang, Y.; Zheng, D.; Lu, X.; Tong, Y. Activated Carbon Fiber Paper with Exceptional Capacitive Performance as a Robust Electrode for Supercapacitors. J. Mater. Chem. A 2016, 4, 5828-5833.

(34) Zhang, H.; Yang, J.; Hou, H.; Chen, S.; Yao, H. NitrogenDoped Carbon Paper with 3d Porous Structure as a Flexible FreeStanding Anode for Lithium-Ion Batteries. Sci. Rep. 2017, 7, No. 7769.

(35) Aryal, N.; Halder, A.; Zhang, M.; Whelan, P. R.; Tremblay, P. L.; Chi, Q.; Zhang, T. Freestanding and Flexible Graphene Papers as Bioelectrochemical Cathode for Selective and Efficient $\mathrm{CO}_{2}$ Conversion. Sci. Rep. 2017, 7, No. 9107.

(36) Gross, A. J.; Holzinger, M.; Cosnier, S. Buckypaper Bioelectrodes: Emerging Materials for Implantable and Wearable Biofuel Cells. Energy Environ. Sci. 2018, 11, 1670-1687.

(37) Park, S. J.; Chang, Y. H.; Moon, C. W.; Suh, D. H.; Im, S. S.; Kim, Y. C. A Study of Atmospheric Plasma Treatment on Surface Energetics of Carbon Fibers. Bull. Korean Chem. Soc. 2010, 31, 335338.

(38) Wang, S. C.; Chang, K. S.; Yuan, C. J. Enhancement of Electrochemical Properties of Screen-Printed Carbon Electrodes by Oxygen Plasma Treatment. Electrochim. Acta 2009, 54, 4937-4943.

(39) Ni, Z.; Wang, Y.; Yu, T.; Shen, Z. Raman Spectroscopy and Imaging of Graphene. Nano Res. 2008, 1, 273-291.

(40) Saito, R.; Hofmann, M.; Dresselhaus, G.; Jorio, A.; Dresselhaus, M. S. Raman Spectroscopy of Graphene and Carbon Nanotubes. Adv. Phys. 2011, 60, 413-550.

(41) Dresselhaus, M. S.; Jorio, A.; Souza Filho, A. G.; Saito, R. Defect Characterization in Graphene and Carbon Nanotubes Using Raman Spectroscopy. Philos. Trans. R. Soc., A 2010, 368, 5355-5377.

(42) Eckmann, A.; Felten, A.; Verzhbitskiy, I.; Davey, R.; Casiraghi, C. Raman Study on Defective Graphene: Effect of the Excitation Energy, Type, and Amount of Defects. Phys. Rev. B 2013, 88, No. 035426.

(43) Nanda, S. S.; Kin, M. J.; Yeom, K. S.; Seong, S. S. A.; Ju, H.; Yi, D. K. Raman Spectrum of Graphene with Its Versatile Future Perspectives. TrAC, Trends Anal. Chem. 2016, 80, 125-131.

(44) Zhu, W.; Zhang, X.; Yin, Y.; Qin, Y.; Zhang, J.; Wang, Q. InSitu Electrochemical Activation of Carbon Fiber Paper for the Highly Efficient Electroreduction of Concentrated Nitric Acid. Electrochim. Acta 2018, 291, 328-334.

(45) Raymundo-Piñero, E.; Azaïs, P.; Cacciaguerra, T.; CazorlaAmorós, D.; Linares-Solano, A.; Béguin, F. $\mathrm{KOH}$ and $\mathrm{NaOH}$ Activation Mechanisms of Multiwalled Carbon Nanotubes with Different Structural Organisation. Carbon 2005, 43, 786-795.

(46) Liu, J.; Miao, H.; Lakshmanan, S.; Wang, L. C.; Tsai, R. H. Fabrication of Metal Alloy-Deposited Flexible MWCNT Buckypaper for Thermoelectric Applications. J. Nanomater. 2013, 2013, No. 635647.

(47) Kondratowicz, I.; Nadolska, M.; Şahin, S.; Łapiński, M.; Prześniak-Welenc, M.; Sawczak, M.; Eileen, H. Y.; Sadowski, W.; Żelechowska, K. Tailoring Properties of Reduced Graphene Oxide by Oxygen Plasma Treatment. Appl. Surf. Sci. 2018, 440, 651-659.

(48) Jiao, L.; Chua, Z. Y.; Moon, S. K.; Song, J.; Bi, G.; Zheng, H.; Lee, B.; Koo, J. Laser-Induced Graphene on Additive Manufacturing Parts. Nanomaterials 2019, 9, No. 90.

(49) Banciu, C.; Lungulescu, E. M.; Bara, A.; Leonat, L.; Teisanu, A. 3D Graphene Network Investigation by Raman Spectroscopy. Optoelectron. Adv. Mater., Rapid Commun. 2017, 11, 368-372.

(50) Bourquard, F.; Bleu, Y.; Loir, A. S.; Caja-Munoz, B.; Avila, J.; Asensio, M. C.; Raimondi, G.; Shokouhi, M.; Rassas, I.; Farre, C.; Chaix, C.; Barnier, V.; Jaffrezic-Renault, N.; Garrelie, F.; Donnet, C. Electroanalytical Performance of Nitrogen-Doped Graphene Films Processed in One Step by Pulsed Laser Deposition Directly Coupled with Thermal Annealing. Materials 2019, 12, No. 666.

(51) Olejniczak, A.; Skuratov, V. A. Effect of Swift Heavy Ion Irradiation on Single- and Multiwalled Carbon Nanotubes. Nucl. Instrum. Methods Phys. Res., Sect. B 2014, 326, 33-36.

(52) Sahoo, G.; Polaki, S. R.; Ghosh, S.; Krishna, N. G.; Kamruddin, M.; Ostrikov, K. Plasma-Tuneable Oxygen Functionalization of Vertical Graphenes Enhance Electrochemical Capacitor Performance. Energy Storage Mater. 2018, 14, 297-305.

(53) Park, S. J.; Chang, Y. H.; Moon, C. W.; Suh, D. H.; Im, S. S.; Kim, Y. C. A Study of Atmospheric Plasma Treatment on Surface Energetics of Carbon Fibers. Bull. Korean Chem. Soc. 2010, 31, 335338.

(54) Kumar, N.; Srivastava, V. C. Simple Synthesis of Large Graphene Oxide Sheets Via Electrochemical Method Coupled with Oxidation Process. ACS Omega 2018, 3, 10233-10242.

(55) Leuaa, P.; Priyadarshani, D.; Choudhury, D.; Maurya, R.; Neergat, M. Resolving charge-transfer and mass-transfer processes of $\mathrm{VO}^{2+} \mathrm{VO}_{2}{ }^{+}$redox species across the electrode/electrolyte interface using electrochemical impedance spectroscopy for vanadium redox flow battery. RSC Adv. 2020, 10, 30887-30895.

(56) Randviir, E. P. A Cross Examination of Electron Transfer Rate Constants for Carbon Screen-Printed Electrodes Using Electrochemical Impedance Spectroscopy and Cyclic Voltammetry. Electrochim. Acta 2018, 286, 179-186.

(57) White, A. M.; Slade, R. Investigation of Vapour-Grown Conductive Polymer/Heteropolyacid Electrodes. Electrochim. Acta 2003, 48, 2583-2588.

(58) Yao, W.; Wang, J.; Hao, L.; Yun, L. Flexible $\alpha-\mathrm{MnO}_{2}$ paper formed by millimeter-long nanowires for supercapacitor electrodes. $J$. Power Sources 2014, 247, 824-830.

(59) Li, J.; Li, Y.; Zhang, Y.; Wei, G. Highly Sensitive Molecularly Imprinted Electrochemical Sensor Based on the Double Amplification by an Inorganic Prussian Blue Catalytic Polymer and the Enzymatic Effect of Glucose Oxidase. Anal. Chem. 2012, 84, 1888-1893.

(60) Gimenes, D. T.; Nossol, E. Effect of Light Source and Applied Potential in the Electrochemical Synthesis of Prussian Blue on Carbon Nanotubes. Electrochim. Acta 2017, 251, 513-521.

(61) Karykin, A. A.; Karyakina, E. E. Prussian Blue-Based Àrtificial Peroxidase' as a Transducer for Hydrogen Peroxide Detection. Application to Biosensors. Sens. Actuators, B 1999, 57, 268-273.

(62) Karyakin, A. A. Prussian Blue and Its Analogues: Electrochemistry and Analytical Applications. Electroanalysis 2001, 13, 813819.

(63) Adekoya, G. J.; Sadiku, R. E.; Hamam, Y.; Ray, S. S.; Mwakikunga, B. W.; Folorunso, O.; Adekoya, O. C.; Lolu, O. J.; Biotidara, O. F. Pseudocapacitive Material for Energy Storage Application: PEDOT and PEDOT:PSS. In AIP Conference Proceedings; AIP Publishing LLC, 2020; Vol. 2289, p 020073.

(64) Volkov, A.; Wijeratne, K.; Mitraka, E.; Ail, U.; Zhao, D.; Tybrandt, K.; Andreasen, J. W.; Berggren, M.; Crispin, X.; Zozoulenko, I. V. Understanding the Capacitance of PEDOT:PSS. Adv. Funct. Mater. 2017, 27, No. 1700329. 
(65) Wang, Z.; Tammela, P.; Huo, J.; Zhang, P.; Stromme, M.; Nyholm, L. Solution-Processed Poly(3,4-Ethylenedioxythiophene) Nanocomposite Paper Electrodes for High-Capacitance Flexible Supercapacitors. J. Mater. Chem. A 2016, 4, 1714-1722. 